\title{
Erratum: Guide to risk assessment for reservoir safety management - addendum No 2
}

Michael Wallis

HR Wallingford
Alan Brown

Stillwater Associates
The Guide was produced under the EA-Defra flood risk management R\&D programme and published in June 2013, being the update to the Interim Guide (ICE) published in 2004. It can be downloaded from

https://www.gov.uk/government/publications/guide-to-riskassessment-for-reservoir-safety-management

The Guide comprises three volumes:

Volume 1 (32 pages) - provides a high level overview of the use of quantitative risk assessment

Volume 2 (312 pages) - provides the methodology and is in two parts, the first presenting the three tiers of assessment (qualitative, simplified quantitative and quantitative), and the second providing supporting information on different aspects of each part of the risk assessment

Volume 3 - reports on the pilot studies which were used to test the process and provide feedback on how it could be improved.

Feedback on use of the Guide has identified a number of typographic and other corrections required. Addendum No 1 was published in Dams and Reservoir Safety in 2014 (volume 24(1) pp 9 to 18). However, some further clarifications have been identified as set out below.

Readers are encouraged to use the Guide as part of Section 10 inspection assessments and other reservoir safety management activities.

Supervising Engineers are encouraged to use Stepla, the identification of failure modes, as described in Section $7 \cdot 1$ (pages 58 to 63), with supporting information in Section 16.4. Where more detailed evaluation is warranted, the event tree process described in Section 8.3.1 can be applied to any failure mode.

All users are encouraged to feedback any additional corrections, areas for improvement or further research to Mike Wallis (m.wallis@hrwallingford.co.uk), or to Dave Hart at the Environment Agency (david.hart@environment-agency.gov.uk).
The following amendments should be made to the guide as published in June 2013:

\begin{tabular}{|c|c|c|}
\hline Section & Page & Erratum \\
\hline Table $8 \cdot 2$ & 72 & $\begin{array}{l}\text { Replace bottom row in right hand column by: } \\
\text { Adjustment of anchor point } 0 \text { (best } \\
\text { condition dam) for intrinsic condition score } \\
\text { should use interpolation in log-linear space, } \\
\text { not a linear interpolation (ref Figure } 17 \cdot 2 \text { of } \\
\text { RARS). This the adjusted anchor point for } \\
\text { score } 0 \text { should be: } \\
\left.\text { AP(A) }=10^{\wedge} \text { (Log AP( } 0\right)+I C S * 3 / 10 \text { ) } \\
\text { Where } \\
\text { AP(O) = value in Table } 8 \cdot 16 \\
\text { ICS = Intrinsic condition score } \\
\text { AP(A) - anchor point after correction for } \\
\text { Intrinsic condition } \\
\text { The factor } 3 \text { in the second term is log } 10 \text { (1000) } \\
\text { and reflects the range of } 1000 \text { in probability } \\
\text { of anchor point } 0 \text { for ICS varying between } 0 \\
\text { and } 10 \text {. } \\
\text { This correction applies to both embankments } \\
\text { and appurtenant structures. For those who } \\
\text { prefer graphical presentation the } \\
\text { relationships are plotted on Figure } 1 \text { and can } \\
\text { be read directly from that figure. }\end{array}$ \\
\hline Box 8.3 & 75 & $\begin{array}{l}\text { The adjustment for intrinsic condition should } \\
\text { be deleted and replaced by a log-linear } \\
\text { interpolation as above }\end{array}$ \\
\hline Box $8 \cdot 3$ & 75 & $\begin{array}{l}\text { When assessing the current condition score } \\
\text { some users find it helpful to also include the } \\
\text { other contributory factors given in Sections } \\
4 \cdot 4 \cdot 2,5 \cdot 4 \cdot 2 \text { and } 5 \cdot 5 \cdot 2 \text { of the Interim Guide } \\
\text { to QRA (ICE, 2004) for example monitoring } \\
\text { (instrumentation), ease of inspection, } \\
\text { reservoir operation and ability to lower the } \\
\text { reservoir in an emergency }\end{array}$ \\
\hline $\begin{array}{l}\text { Table } 8 \cdot 7 \\
\text { and } \\
\text { Box } \\
8 \cdot 10\end{array}$ & 89 & $\begin{array}{l}\text { The suggested base values of crest width, } \\
\text { freeboard and offset to water line for a } \\
\text { median dam are for a typical dam of say } 5 \\
\text { to } 15 \mathrm{~m} \text { height ( } 25 \% \text { to } 75 \% \text { of UK dams), } \\
\text { and should be varied for larger and smaller } \\
\text { dams (perhaps related to \% of height) i.e. } \\
\text { the conditional probability should compare } \\
\text { the subject dam to a typical values for a dam } \\
\text { of the same height. }\end{array}$ \\
\hline
\end{tabular}




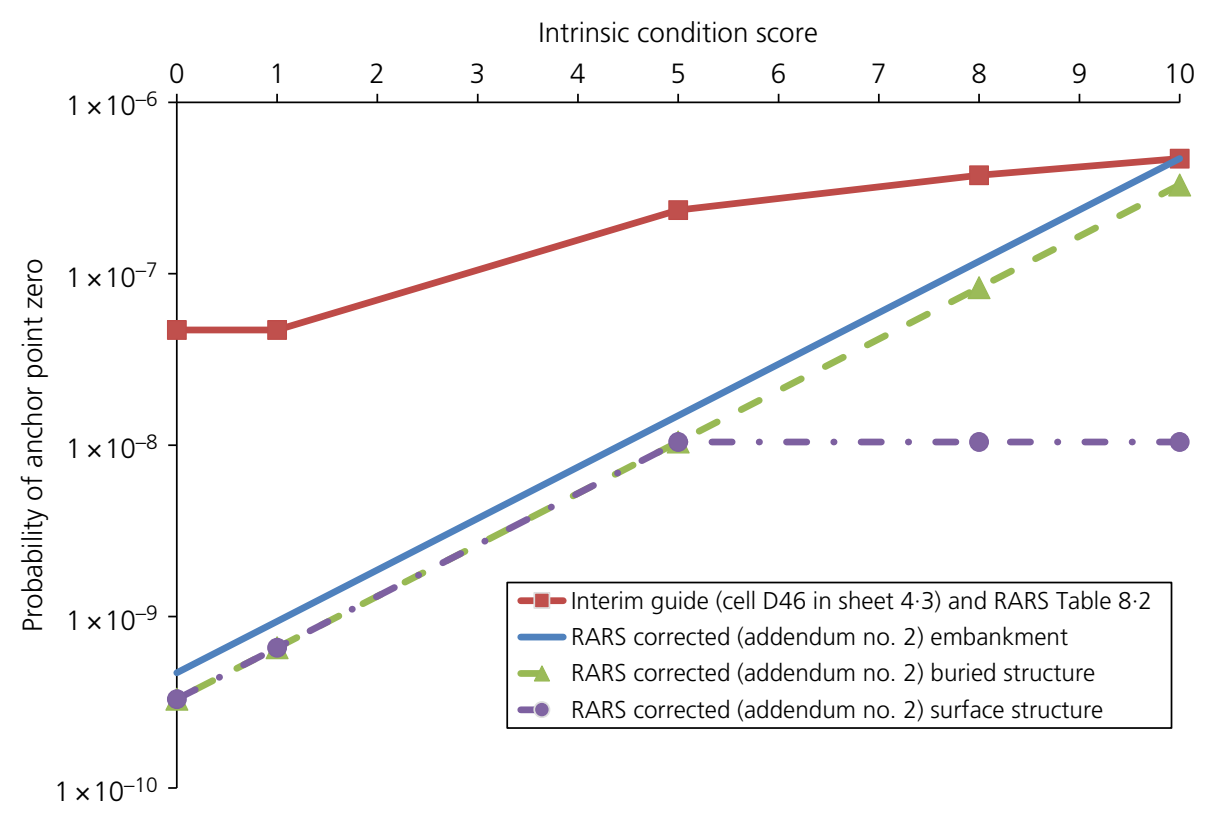

Figure 1. Effect of adjustment for Intrinsic condition on anchor point 0

The change from linear to linear-log interpolation for anchor point zero is a significant clarification and will reduce the probability of failure of embankment dams due to internal threats by typically an order of magnitude. This is illustrated in Figure 1. This is consistent with Figure 8.2 of RARS and is considered reasonable, on that basis that for a modern well built dam the following probabilities of failure (release of reservoir) would be expected to be similar

- Internal threats, when the embankment and foundation incorporate filters and other defensive measures

- Floods, when the spillway is designed to pass PMF with a wave freeboard of $0.6 \mathrm{~m}$ 